\section{K. Breitkreutz}

Dionino Colleluori

Yun-long $\mathrm{Ge}$, Jing-yun Wang

Amol Kumar Jha, T. R. Ramchandran, G. S. Upadhyaya

H. S. Khatak, V. Seetharaman, J. B. Gnanamoorthy

Trilok Singh, G. Sundar Sarma
Über Rechnerprogramme zur Ermittlung von Kugelverteilungen aus ebenen Schnittkreisdurchmessern

Computer Programs to Establish Sphere Distributions from Plane Cut Circle Diameters

Improved Etching Methods for Quantitative Metallography of HSLA Multi-Phase Steels

Verbesserte Ätzverfahren für die quantitative Metallographie von mehrphasigen HSLA-Stählen

Transformation of MC Carbide in Cast Ni-Base Superalloys

Die Umwandlung von MC-Karbiden in NickelbasisGußsuperlegierungen

Transmission Electron Microscopy of Al-Cu Based Powder Metallurgical Composites

Durchstrahlungselektronenmikroskopie von pulvermetallurgisch hergestellten $\mathrm{Al}-\mathrm{Cu}$-Verbundwerkstoffen

Failure Analysis of Welded Helium Tanks

Schadensanalyse von geschweißten

Heliumtanks

Failure of Azimuth Gear Casing Cover

Bruch im Gehäuse eines Azimuth-Getriebes

Mitteilungen/Information 583

Persönliches/Personal Notes 584

Tagungskalender/Meeting Diary 585

Literatur-Notizen/Literature Reviews 586 

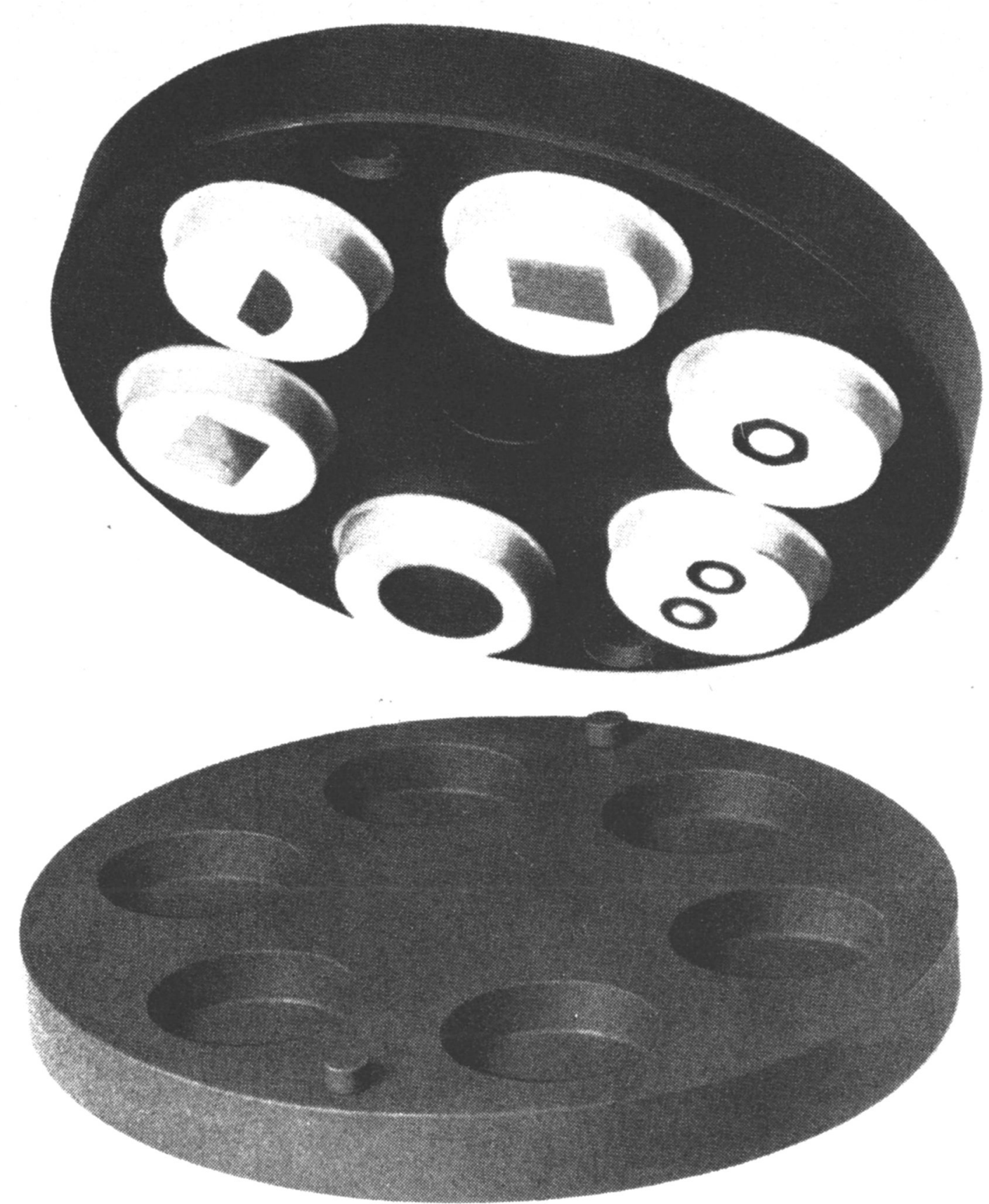

\section{Direkt einbetten, sofort schleifen: Der neue Technotron Universal-Probenhalter}

Automatische oder halbautomatische Geräte erleichtern in immer größerem Maße das Schleifen und Polieren metallografischer Proben. Aber noch immer verursacht das Ein- und Ausbetten der Proben, das Einspannen im Probenhalter sowie das Ausrichten und Nivellieren viel Aufwand, Zeit und Kosten.

Kulzer \& Co $\mathrm{GmbH}$

Wehrheim/Ts. Bereich Technik Postfach 1320 D-6382 Friedrichsdorf 1 Telefon (0 61 72) 7021

Telex 415863 kulz d
Durch den Einsatz des patentierten Technotron Universal-Probenhalters ist dies nicht mehr notwendig. Sein Funktionsprinzip: Das Oberteil ist als Probenhalter zum direkten Befestigen an der Antriebswelle der Schleif- und Polierautomatik geeignet das Unterteil dient als Einbettform.

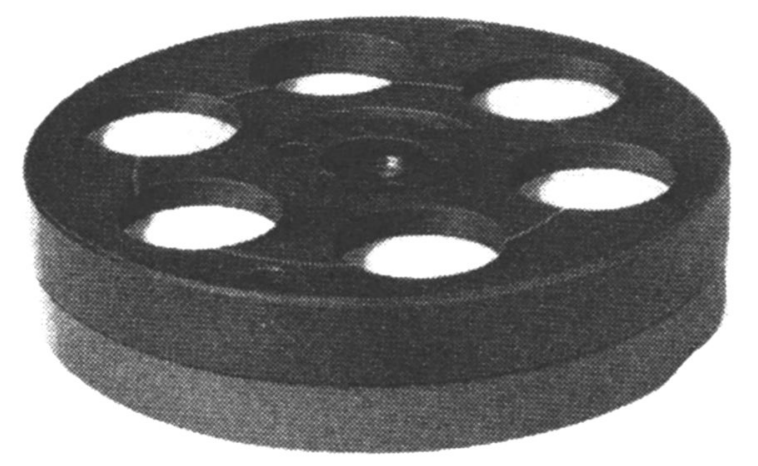

Diese Kombination spart Zeit und Geld: Sie betten die zu bearbeitenden Proben direkt im UniversalProbenhalter ein und beginnen nach Aushärten der Einbettmasse sofort mit dem Schleifen.

Alle vorhandenen automatischen Schleif- und Poliergeräte mit fester Probenführung können nachträglich mit dem Technotron UniversalProbenhalter ausgerüstet werden.

\section{Kulzer:}

